\title{
Carotid body tumour-- A rare case report
}

\author{
Dheeraj Sharma ${ }^{1}$, Hema Chaudhary ${ }^{2,}$ Sangeeta Aneja ${ }^{3}$ \\ ${ }^{1}$ Senior Resident, Department of cardiothoracic surgery, SMS Medical college ,Jaipur \\ ${ }^{2}$ Resident, ${ }^{3}$ Professor, Department of Radio diagnosis, L.L.R.M Medical College, Meerut
}

\begin{abstract}
A carotid body tumour is a rare presentation of an extra-adrenal pheochromocytoma which typically present as a slow growing, painless neck mass found along the anterior border of the sternocleidomastoid muscle, and careful preoperative evaluation is required to find out the functional and vascular status of these tumours. Carotid body paragangliomas were diagnosed by Doppler ultrasound, carotid artery angiography, cranial computed tomography and magnetic resonance imaging. These tumours are generally benign but possess aggressive local growth potential. Therefore, definitive treatment requires surgical resection. Here we describe a case of a carotid body tumour in a 45-year-old female presenting with a neck mass, its evaluation, management and the final outcome and review the most recent literature on this unusual topic.
\end{abstract}

Keywords: carotid body paraganglioma, carotid body tumour, paraganglioma, phaeochromocytoma.

\section{Introduction}

Carotid body was first described by Van Haller. Carotid body paraganglioma are rare neoplasm, commonly benign, account for only $0.5 \%$ of all body tumours, they mimic other paragangliomas of the body (glomus jugulare, glomus tympanicum, and pheochromocytoma).

The tumour arises from paraganglionic cells of the carotid body which develops from both mesodermal elements of the third branchial arch and neural elements originating from the neural crest ectoderm. Paragangliomas are painless tumours that grow very slowly. They originate from neural crest cells that have migrated with ganglionic cells from the autonomic nervous system.

\section{Case Report}

'A 45-year-old female patient presented with a neck swelling that had persisted for 2 years. On physical examination, a pulsating firm painless mass measuring about $3 \times 3 \mathrm{~cm}$ in size was found on the right side of her neck, near the angle of the mandible in right juglocarotid region (figure 1). There were no pressure symptom \& more mobile transversely than vertically. Pulsations were felt on deep palpation and a faint bruit was heard on auscultation. Doppler ultrasonography showed a highly ill defined hypo echoic mass lesion with increase vascularity at the bifurcation of the common carotid artery causing splaying of right external \& internal carotid artery with no luminal compromise (figure $2 \& 3$ ). Contrast-enhanced Computed tomography demonstrated a well-circumscribed lobulated heterogeneously intensly enhancing soft tissue density mass of size $2.5 \mathrm{~cm} \times 1.6$ $\mathrm{cm} \times 1.6 \mathrm{~cm}$ and located at the bifurcation of the right carotid artery\& causing splaying of external \& internal carotid artery with normal calibre of these arteries, laterally it abutting the anterior wall of right internal juglar vein. No infiltration into adjacent structures is seen(figure 4) . Magnetic resonance (MR) imaging showed a $1.8 \mathrm{~cm} \times 1.8 \mathrm{~cm} \times 1 \mathrm{~cm}$ lobulated oval well defined lesion mass in the right carotid space, with multiple flow voids with intense enhancement on T2-weighted images with splaying of external \& internal carotid artery(figure 5) . Carotid angiography showed a vascular blush at the widened carotid bifurcation . Mass is not intrinsic to blood vessels \& patency of the artery was preserved(figure 6). This finding was considered to be consistent with a diagnosis of glomus caroticum(carotid body tumour).

The neck was explored by a vertical incision under general anaesthesia. A homogeneous tumour with a smooth contour and approximately $3 \mathrm{~cm}$ long was observed at the carotid bifurcation, it was classified as a grade-2 tumour according to the Shamblin classification system (figure 7). The common, external, and internal carotid arteries were isolated. . Excision of a fairly vascular tumour at the bifurcation was possible. Small arterial branches arising from the bifurcation had to be ligated. No bypass was necessary( figure 8). The postoperative recovery was uneventful. The patient is alive and asymptomatic. Histologically, the tumour was composed of Nests of fairly uniform epitheloid cells with finely granular pale eosinophilic cytoplasm, with round nuclei were seen surrounded by vascular stroma. Mitotic figures were absent and there were a few neural elements. Urinary MNs, VMA and 131I-MIBG scintigraph were normal. 


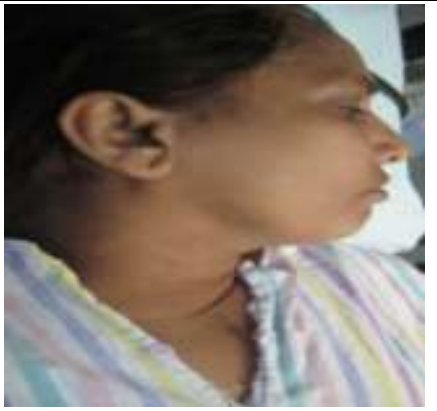

Figure 1: Mass anterior to the right sternomastoid muscle.

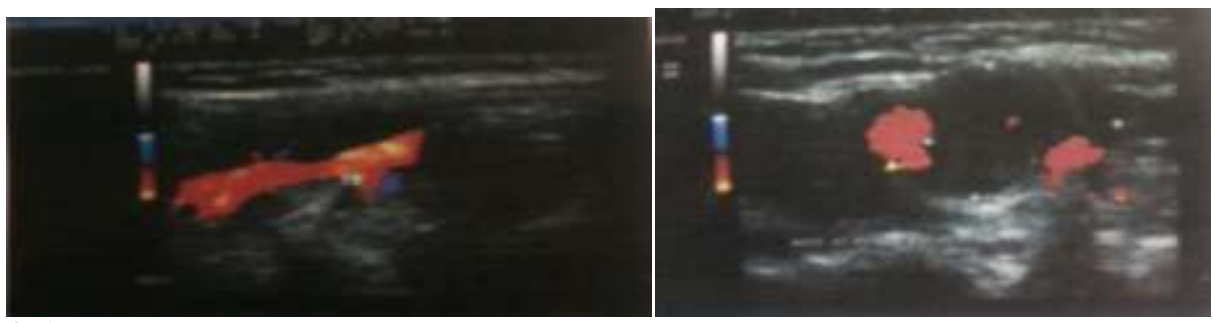

Figure 2 \& 3. Doppler ultrasonography showed a highly ill defined hypoechoic mass lesion with increase vascularity at the bifurcation of the common carotid artery causing splaying of right external \& internal carotid artery with no luminal compromise .

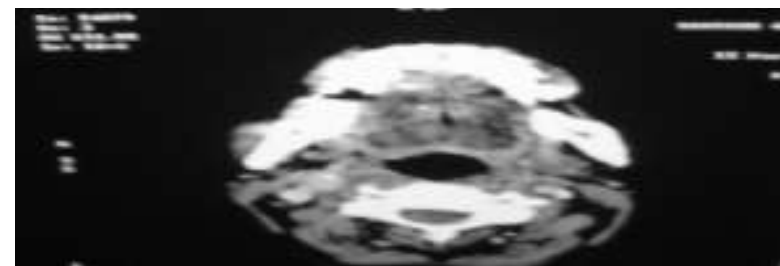

Figure 4. Contrast-enhanced Computed tomography demonstrated a well-circumscribed lobulated heterogeneously intensly enhancing soft tissue density mass of size $2.5 \mathrm{~cm} \times 1.6 \mathrm{~cm} \times 1.6 \mathrm{~cm}$ and located at the bifurcation of the right carotid artery\& causing splaying of external $\&$ internal carotid artery with normal calibre of these arteries, laterally it abutting the anterior wall of right internal juglar vein. No infilteration into adjacent structures is seen

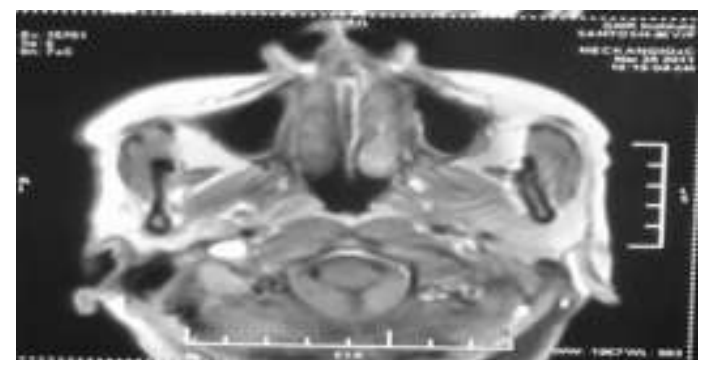

Figure 5. Magnetic resonance (MR) imaging showed a $1.8 \mathrm{~cm} \times 1.8 \mathrm{~cm} \times 1 \mathrm{~cm}$ lobulated oval well defined lesion mass in the right carotid space, with multiple flow voids with intense enhancement on T2-weighted images with splaying of external \& internal carotid artery.

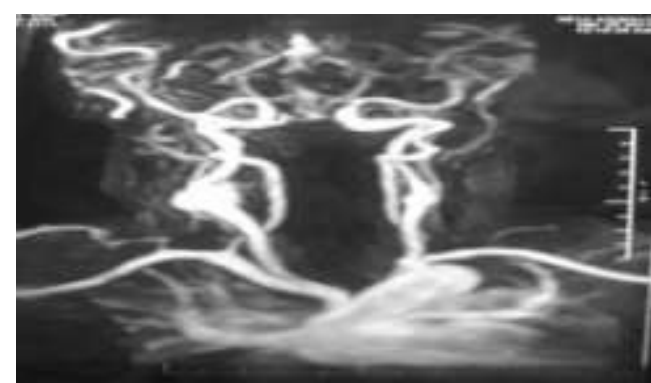

Figure 6. Carotid angiography showed a vascular blush at the widened carotid bifurcation . Mass is not intrinsic to blood vessels \& patency of the artery was preserved 


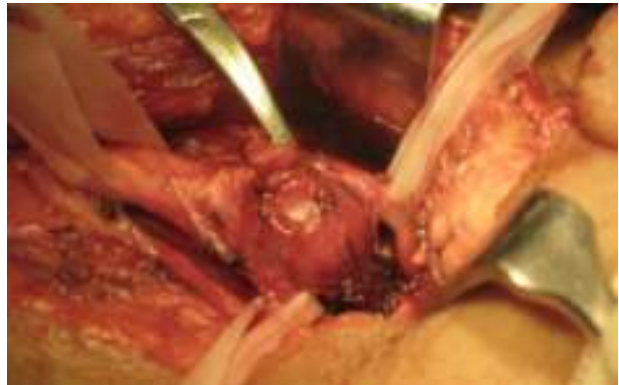

Figure 7. A homogeneous tumor with a smooth contour and approximately $3 \mathrm{~cm}$ long was observed at the carotid bifurcation

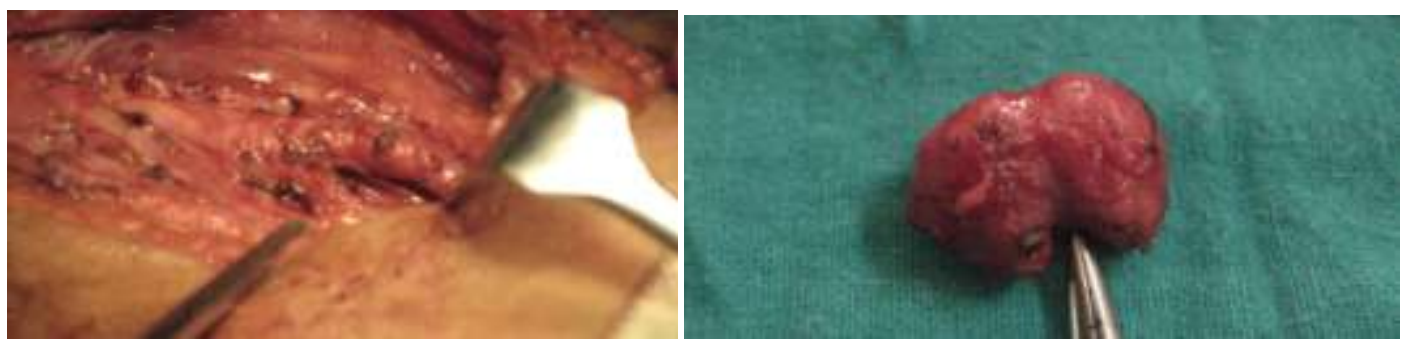

Figure 8: Excision of a fairly vascular tumour at the bifurcation with No bypass was necessary

\section{Discussion}

Carotid body is a highly specialized round, reddish-brown organ $2-6 \mathrm{~mm}$ in size located in the semi adventitial tissue of the common carotid artery bifurcation. Supplied by a feeding vessels runs from the ascending pharyngeal artery a branch of external carotid artery and innervated through the gloss pharyngeal and vagus nerves ${ }^{2,3}$. Physiologically, the carotid body functions as a chemoreceptor organ that is stimulated by hypoxia, hypercapnea, and acidosis, it is involved in the control of blood pressure, heart rate, and respiration in response to changes in these parameters by increasing sympathetic flow ${ }^{4}$. The histological appearance of the carotid body includes two types of cells: Type 1 (chief cells) which are APUD (amine precursors uptake decarboxylation) type cells with copious cytoplasm and large round or oval nuclei. Their cytoplasm contains dense core granules that store and release catecholamines. Hyperplasia of the chief cells leads to enlargement of the paraganglia during chronic hypoxia. Type 2 cells (sustentacular cells) which are elongated cells that closely resemble Schwann cells. These cells are arranged into clusters with a core of chief cells surrounded by sustentacular cells embedded in a fibrous stroma ${ }^{1,4,5}$.

Carotid body paragangliomas is more common in women with female-to-male ratio of 2.7:1,6 , they are predominantly a disease of the middle age with the average age of onset at 45 years. ${ }^{7}$

Carotid body paraganglioma was reported to be malignant in $10 \%$, familial in $10 \%$, and bilateral in $10 \%$ of sporadic cases, bilaterality may reach $30 \%$ in the familial cases. ${ }^{4,8}$

Metastatic malignant CBP occurs in 5\% of cases, and usually metastasis confined to the neck. Multicentricity of paragangliomas can occur in up to $25 \%$ of patients.

Carotid body paragangliomas are slow growing painless masses localized in the neck, anterior to the sternocleidomastoid muscle at the level of the hyoid bone. As the tumour grows, dysphagia, odynophagia, dysphonia, and symptoms due to compression of cranial nerves 9 to 12 may be seen ${ }^{9-11}$. The most commonly involved cranial nerve is the vagus, up to one third of all cases will show cranial nerve palsies. ${ }^{8}$ Physical examination of patients with CBP characteristically reveals a rubbery, non tender mass in the upper neck along the anterior border of the sternomastoid muscle and the lesion is more freely movable laterally than vertically (fontaine`s sign). ${ }^{2,5}$ Occasionally the tumour mass may transmit the carotid pulse or demonstrate a bruit or thrill.

Carotid arterial angiography is the most valuable diagnostic technique. ${ }^{10,12}$ It can detect multiple lesions, tumour size and vascularity, and the major vascular tributaries perusing the tumour. Pathognomically, a specific perfusion increase (Lir sign) at the carotid bifurcation can be seen due to the tumor ${ }^{10}$.Arteriographic imaging should be carried out bilaterally because of the possibility of bilateral tumors. ${ }^{9,10,13}$ In cases of bilateral tumours, serum catecholamine levels as well as urinary vanilmandelic acid and metanephrine levels should be assessed. $^{12,14}$ Magnetic resonance imaging and contrast enhanced computed tomography scans are additional noninvasive diagnostic tools. With magnetic resonance imaging, paragangliomas smaller than $0.8 \mathrm{~cm}$ in diameter can be detected ${ }^{9,12}$. Biopsy is contraindicated in cases of paraganglioma. Paragangliomas are generally sporadic in character; they are hereditary with an autosomal dominant pattern in $7 \%$ to $9 \%$ of cases. Patients with a family history and hypertensive palpitation attacks with flushing should be assessed. ${ }^{12,14}$ 
Surgery is the first choice of treatment. Radiotherapy has been used as the sole treatment in a few cases, and the short-term results are disputable ${ }^{15}$. Radiotherapy may be considered as an alternative modality for an elderly patient in poor general status, whereas surgical treatment is preferred in young patients ${ }^{10-12}$.

Tumour classification (Shamblin) is based on the size and the difficulty of surgical resection. A grade-1 tumour is small and easily resected from vascular elements. Grade 2 is a medium-sized tumour closely associated with vascular structures, which can be resected by careful subadventitial dissection. A grade-3 tumour is large and enfolded by the carotid arteries; it can be resected only by partial or total vascular resection requiring vascular replacement ${ }^{17}$. A transcervical approach is usually preferred, but in superiorly localized carotid paragangliomas, a cranial basilar approach can be used ${ }^{15}$.The most important principle is to preserve the integrity of the internal carotid artery. If necessary, the external carotid artery can be sacrificed ${ }^{8-12}$. Defects in the common or internal carotid arteries must be repaired immediately and graft replacement may be necessary ${ }^{9,16}$.

\section{References}

[1] Amr A. Attia, Hassan Abdalla, Sherief Mamoun and Hesham El-Sebai. Carotid bodyganglioma; Journal of the Egyptian nat. cancer inst. ,Vol.13,No.2,June:79-84,2001.

[2] Lazar B Davidovic, Vojko B Djukic, Dragan M Vasic, Radomir P Sindjelic Stevo N Duvnjak,Diagnosis and treatment of carotid body paraganglioma: 21 years of experience at a clinical center of Serbia World Journal of Surgical Oncology 2005, 3:10 doi:10.1186/1477-7819-3-10.

[3] Milewski C: Morphology and clinical aspects of paragangliomas in the area of head-neck. HNO 1993, 41:526-531.

[4] Fernando E. Kafie, MD and Julie A. Freischlag,Carotid Body Tumors: The Role ofPreoperative Embolization, Ann Vasc Surg 2001; 15: 237-242.

[5] Patetsios P, Gable DR, Garrett WV, Lamont JP, Kuhn JA, Shutze WP, et al management of carotid body paragangliomas and reviews of 30 year experience. Ann Vasc Surg. 2002May;16(3):331-8.

[6] Ridge BA, Brewster DC, Darling RC, Cambria RP, LaMuraglia GM, Abbott WM: Familial carotid body tumors: incidence and implications. Ann Vasc Surg 1993, 7:190-194.

[7] Kotelis D, Rizos T, Geisbüsch P, Attigah N, Ringleb P, Hacke W, Allenberg JR, BöcklerD.Late outcome after surgical management of carotid body tumors from a 20-year single-center experience, Langenbecks Arch Surg. 2008 Jul 17.

[8] Dimakakos P., Kotsis T, Carotid body paraganglioma: review and surgical management, Eur J Plast Surg (2001) 24:58-65.

[9]. van der Mey AG, Jansen JC, van Baalen JM. Management of carotid body tumors. Otolaryngol Clin North Am 2001;34:907-24.

[10]. Wang SJ, Wang MB, Barauskas TM, Calcaterra TC. Surgical management of carotid body tumors. Otolaryngol Head Neck Surg 2000;123:202-6.

[11]. Plukker JT, Brongers EP, Vermey A, Krikke A, van den Dungen JJ. Outcome of surgical treatment for carotid body paraganglioma. Br J Surg 2001;88:1382-6.

[12]. Westerband A, Hunter GC, Cintora I, Coulthard SW, Hinni ML, Gentile AT, et al. Current trends in the detection and management of carotid body tumors. J Vasc Surg 1998; 28:84-93.

[13]. Thabet MH, Kotob H. Cervical paragangliomas: diagnosis, management and complications. J Laryngol Otol 2001; 115:467-74.

[14]. Balatsouras DG, Eliopoulos PN, Economou CN. Multiple glomus tumors. J Laryngol Otol 1992;106:538-43.

[15]. McCaffrey TV, Meyer FB, Michels VV, Piepgras DG, Marion MS. Familial paragangliomas of the head and neck. Arch Otolarnygol Head Neck Surgery 1994; 120:1211-6.

[16]. Pisanu A, Cois A, Uccheddu A, Cagetti M. Carotid body tumour. Case report and literature review [Italian]. Minerva Chir 2001;56:101-9.

[17]. Nader M. Albsoul, Moaath M. Alsmady, Mahmoud I. Al-Aardah.Carotid Body Paraganglioma Management and Outcome European Journal of Scientific Research. ISSN 1450-216X Vol.37 No.4 (2009), pp.567-574 